\title{
From tradition to innovation: plaster at risk under severe climatic condi- tions
}

S.Erba

Politecnico di Milan, Energy Dept., Milan, Italy

\author{
A. Sansonetti \\ ICVBC-CNR, Milan, Italy \\ E. Rosina \\ Politecnico di Milan, ABC Dept., Milan, Italy
}

R. Moioli

Politecnico di Milan, ABC Dept., Milan, Italy

G. Suardi

Restorer, Bianzone (BG), Italy

ABSTRACT: The research identifies strategies to increase the durability of the components of historic buildings and minimize the environmental impacts.

The method has a direct application within the Conservation Plan of Lavello Convent (Lake Como). The study case is particularly representative of the historical building techniques and materials in the Northern Lombardy region. The study case presented the highest risks for the conservation of traditional finishing on site, because of the adverse climate and the particular exposure to rainfall of the exterior north facing plaster. The researchers studied six mortar mixes to identify the durability and compatibility compared to the masonry underneath, for repairing/substituting the exterior plaster of the northern side, which faced the worst conditions. The same formulations were tested on the specimens in the laboratory too.

The diagnostics focused on the characterization and assessment of the water transport phenomena in mortars, through different tests, studying the absorption and vapour transmission properties by means of steady and innovative non-destructive techniques. A second step of the research included the application of protective products on the specimens, and on biocide and protective products on the site and the repetition of the tests. At the end of the experimental tests, the results were implemented in the ongoing Conservation Plan and especially supported the decision process for defining the threshold between maintenance and acceptable damage, and, consequently set the inspection procedures, cycles of maintenance of protective/biocide treatments, and the economic plan.

\section{INTRODUCTION}

The research identifies strategies to increase the durability of the components of historic buildings and minimize the environmental impacts. It deals with several conservation aspects for preserving historic architecture surfaces. The present paper shows the adopted methodology for defining time, procedures and materials to choose the most suitable mortars for maintenance and repairing the existing plaster subject to severe environmental conditions.

The strategy of Preventive and Planned Conservation, meaning Conservation of Built Cultural Heritage as a process in time, foresees a long run vision about transformations and behaviors of the building based on the risks assessment. Furthermore, this vision means that the assessment of future repair conditions bases on a deep knowledge of the chemical/physical characteristics of materials, their vulnerabilities and it implies a broad vision of the building as an open system.
The approach requires an operational tool, the Conservation Plan, which includes several technical documents.

Among them, the Technical Handbook gathers all the available information, re-elaborated for the risks assessment. The re-elaboration produces the list of activities (preventive actions, inspections, monitoring, diagnostics, maintenance and major interventions) for the Conservation Program. The Program defines whom, how and when to carry out each single activities in a Gantt scheme, at medium-long run. Based on the two documents, it is possible to provide a Budgeting plan and a User Handbook, finalized to the management of the building.

The Conservation Plan allows defining both the preliminary analyses, necessary for maintenance works and major interventions, and the monitoring activities for the evaluation of the durability of restoration.

The method has a direct application within the Conservation Plan of Lavello Convent (Lake Como). The study case is particularly representative of the historic building techniques and materials in the Northern Lombardy region. 
The Conservation Plan was generated following awareness that restoration works would not guarantee the long-term conservation of the property.

The opportunity for the implementation of the Preventive and Planned Conservation methodology has been prompted by the call "Diffondere le metodologie innovative per la conservazione programmata del patrimonio storico-architettonico" issued by Fondazione Cariplo.

In 2012 Fondazione Monastero di S. Maria del Lavello, the foundation in charge of the management, presented a project titled "New Life for ancient Walls", which received an award in the same year. The main question was to intervene on the external plaster that was in poor condition. As only few years had passed since the previous restoration works finished, the owners valued the importance of a strategy aimed at optimizing the resources invested, as well as at considering the conservation needs on the mediumlong term. Therefore, the frame of the project is a protection strategy based on the regular care of the building. This care should consist of conservation works as well as checks and maintenance.

A project should encompass a global systemic vision that includes the path from the deep and analytical knowledge to the information management of the future, via the definition of Preventive and Planned Conservation activities. Thus, conservation changes from an event to a process.

The Conservation Plan had the aim of gathering the widespread information produced before, during and after the restoration, in order to support the coordination of the maintenance/management activities in different stakeholders' care (Fiocca \& Sabatini, 2013).

The Conservation Plan is the operational tool for the implementation of this approach. It should be flexible and customized in accordance with the characteristic of the single building, the available data and the management conditions.

A relevant feature of the Conservation Plan is that it goes along with the building in its development over time, and by updates, it grows and improves, taking part in the coevolution of the building system.

In the specific case, all the available documentation has been examined, thus providing the main source for filling in the identity record and the description of the condition of the property. Above all, the documentation concerning the previous works has been of crucial importance as the most severe problems arose few years after.

The totality of this data enabled knowledge of the artefact in its geometric, material and structural characteristics, helped to assess the conservation condition and to detect the causes of the ongoing decay processes. This way, it has been possible to make a consistent choice of the controls and of the preventive/maintenance actions, which will guarantee the conservation of the material integrity of the building through time.

The aims of the Conservation Plan are: planning the activation of technical and financial resources; scheduling preventive and maintenance activities; preparing a filing system for all types of information; setting up control tools; defining procedures for timely interventions, also involving users; defining respectful uses of the spaces.

The Conservation Plan is a useful tool for the Lavello Foundation to maintain the building in a good state of conservation and to define the roles and responsibilities of all the parties involved in the management of the complex.

The study case presented the highest risks for the conservation of traditional finishing on site, because of the adverse climate and the particular exposure of the exterior northern plaster to rain fall. In fact, the sloping shape of the masonry (much larger at the bottom) and the small protrusion of the eaves prevent any protection of the wall surface from rain.

The existing situation of the Convent has required a detailed diagnosis of the decay patterns and their causes: first of all the need to check the most vulnerable and critical parts, elements and systems that remain under risk of damage due to the environmental and soil conditions, mainly due to high humidity and moisture. From this starting point, it was possible to build a path of conservation where diagnostics has provided the information needed to create the Conservation Plan, prepared in accordance with the Guidelines of the Lombardy Region (Della Torre, 2003) and in particular the contents of the Conservation Program. The head of the conservation of the complex has therefore identified the framework of the needs and priorities and requested the support of experts who could build a medium-long term conservation project.

The project provides the development of a plan of monitoring and preventive steps, including the cyclic maintenance, defining the basis of the recorded and implementable data, and the procedures of interventions, which include the characterization of composition of the mortar to use in case of replacement of parts of the deteriorated plaster. The Conservation Plan took advantage of the results of the assessment of the damage and the results of the experiments (in laboratory and on site) that the researchers designed for testing new materials and cycles of maintenances for damaged plaster. The aim of this was the prolonging of the life of the existing materials and of new ones for as long as possible.

The diagnostic plan concerned three types of survey and analysis:

1. the recognition of the state of adhesion of the plaster in the most decayed parts (northern façade);

2. the plaster characterization and the evaluation of a water-repellent treatment to apply; 
3. the study of the susceptibility of some plaster surface to biodeterioration and the use of biocide treatments;

The researchers investigated points 1 and 2 both on the site and in the laboratory, collecting data on the state of conservation of the façade, studying different mortars before and after the application of the experimental treatment and simulating the heat and moisture transfer which occurs on the northern façade, that produced the most damage from the assessment and survey.

\section{THE STUDY CASE}

Lavello Convent is a complex of buildings (the church, the convents, the courtyards) that recently underwent restoration and at present hosts many useful functions for the local community and, on a larger scale, for the territory.

The Convent dates back to the beginning of 1500 , when the church of the shrine, since considered place of miraculous events, became a place of worship and pilgrimage. The convent suffered many demolitions and transformation, restoration and remakes throughout the centuries, up to the complete restoration finished in 2002.

The building consists of three bodies connected to two internal cloisters. There were different interventions on frescoes, decorations, ornaments and on the pavement dating back to 1400-1500. A western loggia and altars in inlaid marble dates back to the eighteenth century. As documented, the structure had a remarkable evolution, well shown during the recovery of the external plaster.

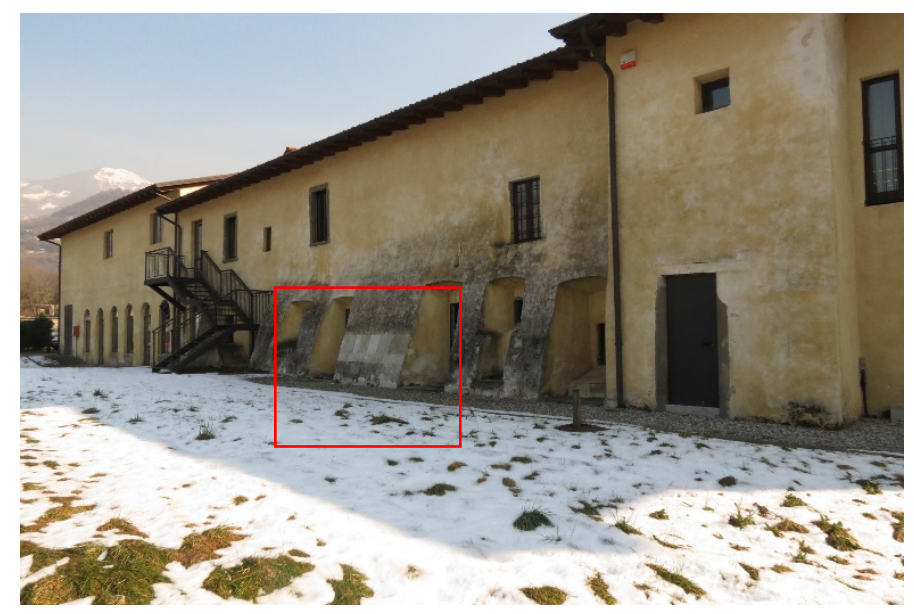

Figure 1 Lavello Convent, Calolziocorte: Northern side. The square frames the areas of application of the biocides under test

Few years after the conclusion of the last restoration works, degradation phenomena appeared that highlighted critical points. In particular, the surveys revealed the poor durability of the plasters applied during the restoration, the damage caused by micro- organisms and plants and the cycle of degradation phenomena due to the environment in which the technological elements are. The phase of assessment of the facades, performed through investigation and thermographic surveys, has provided information about the detected pathologies and their possible causes. The plaster finishing of the facades shows efflorescence, stains, superficial alteration and deposits, crusts, exfoliations, erosion, disgregation, detachments and cracks: the damage mainly deals with the critical exposure to humidity. Therefore, the research focused on the adhesion problems of the finishing caused by water absorption. Aim of the research is to investigate the issue of plaster conservation and evaluate possible strategies of intervention to reduce the damage.

\section{DIAGNOSTIC PLAN AND TECHNIQUES}

The first step was the study of the present conditions of the state of damage of the northern façade. The diagnostic survey aimed at the definition of the chemical and mineralogical composition, the stratigraphic sequence and the state of conservation of some coating materials of the walls, as well as the study of biological colonization present on the facades.

\subsection{Sampling and analytical plan}

The sampling was essentially limited to the removal of fragments of artificial stone materials and fragments supporting biological growth. The researchers of ICVBC-CNR conduced the sampling in collaboration with the restorer Giuseppina Suardi (on March 6, 2012).

Table 1 shows a selection of the most representative collected samples, a brief description of the materials, their original location.

The analytical plan, carried out on the samples, used both mineralogical (X Ray Diffraction) and Chromatographic analyses (Ionic Chromatography); moreover several observations used optical and scanning electron microscopy. Figure 1 shows a map with the location of samples. The causes and mechanisms of degradation have been the basis for the comparison and integration of data obtained from non-destructive on site measurements (measures of the capacity of absorption of water by contact sponge method UNI11432: 2011, color measurement of opaque surfaces - UNI EN 15886: 2010, observations with portable microscope).

The analytical results highlighted the presence of cement binder in the mortar, often mixed with lime. Soluble salts were present in a worrying content, especially nitrates and sulphates. 
Table 1. Sampling and analytical plan.

\begin{tabular}{|c|c|c|}
\hline $\begin{array}{l}\text { Sam- } \\
\text { ple } \\
\text { Name }\end{array}$ & Location & Description \\
\hline L1 & $\begin{array}{l}\text { North façade - } \\
\text { outdoor. } \\
\text { Central } \\
\text { window }\end{array}$ & Mortar, pink external layer \\
\hline L2 & $\begin{array}{l}\text { North façade - } \\
\text { outdoor. } \\
\text { Central } \\
\text { window }\end{array}$ & Mortar, gray internal layer \\
\hline L3 & $\begin{array}{l}\text { North façade - } \\
\text { outdoor. } \\
\text { Central } \\
\text { window }\end{array}$ & $\begin{array}{l}\text { Mortar, pink external layer } \\
\text { with yellow finishing and } \\
\text { residue of the gray layer un- } \\
\text { derneath }\end{array}$ \\
\hline L4 & $\begin{array}{l}\text { North façade - } \\
\text { outdoor. } \\
\text { Right window } \\
\text { (bricks) }\end{array}$ & $\begin{array}{l}\text { Mortar, pink external layer } \\
\text { with yellow finishing and } \\
\text { residue of the gray layer un- } \\
\text { derneath }\end{array}$ \\
\hline L5 & $\begin{array}{l}\text { North façade - } \\
\text { outdoor. } \\
\text { Right window } \\
\text { (bricks) }\end{array}$ & Mortar with brick residue \\
\hline
\end{tabular}

Most probably, the presence of sulphates is due to the addition of gypsum as setting agent into the cement mix design.

These results have been the basis for the development of the following lines of research:

1) The design of a set of experimental hydraulic mortars with aggregates differentiated as to the grains size distribution: their application and characterization by testing water absorption properties, color aspects, reflectance and their performances over time;

2) Assessing the effectiveness of biocides and water-repellent treatment according to the substrate and the organisms therein (Moreau, et al., 2008).

Regarding the first scope, the researchers designed a series of experimental mortars to apply on the northern façade of Lavello.

The project involved a careful selection of raw materials and their application following the "rules of art", thanks to the collaboration of local workers belonging to the Association "Museo del Muratore".

\subsection{Mortars and protective treatments}

On the base of the results of the previous surveys and analysis, the researchers chose and tested six different lime plaster mortars (\# 1-6). Table 2 reports the mortar mix design. They accurately evaluated the water content in the mixture to obtain a homogeneous degree of workability of the mixture, and a proper porosity in the final material when set. They produced 24 specimens $(5 \times 5 \times 2 \mathrm{~cm}$, four specimens for each mix) to test in the laboratory and furthermore placed the new design mortars on site, on the northern side of the cloister, where the environmental conditions and the moisture levels are more critical (Moropoulou, 2000). The wall was washed with water spray to remove any soluble salts present on the surface. The available area was divided into six bands and the six different formulations of mortars according to the following table were applied.

Table 2. Types of mortar.

\begin{tabular}{|c|c|c|c|}
\hline & Binder & Aggregate & $\begin{array}{l}\mathrm{B} / \mathrm{A} \\
\text { ratio }\end{array}$ \\
\hline 1 & Aerial lime putty & $\begin{array}{l}\text { Pozzolan, fine sand } \\
\text { and sieved sand } 0,4\end{array}$ & $1: 1: 1: 1$ \\
\hline 2 & Aerial lime putty & $\begin{array}{l}\text { Cocciopesto, fine } \\
\text { sand and sieved sand } \\
0,4\end{array}$ & $1: 1: 1: 1$ \\
\hline 3 & $\begin{array}{l}\text { Natural hydraulic } \\
\text { lime NHL 3,5 }\end{array}$ & $\begin{array}{l}\text { Sieved sand } 0,4 \text { and } \\
\text { natural coarse sand }\end{array}$ & $1: 1: 2$ \\
\hline 4 & $\begin{array}{l}\text { Natural hydraulic } \\
\text { lime NHL } 3,5\end{array}$ & Natural coarse sand & $1: 3$ \\
\hline 5 & $\begin{array}{l}\text { Natural hydraulic } \\
\text { lime NHL 3,5 }\end{array}$ & $\begin{array}{l}\text { Cocciopesto, sieved } \\
\text { sand } 0,4 \text { and brick } \\
\text { fragments }\end{array}$ & $1: 1: 1: 1$ \\
\hline 6 & $\begin{array}{l}1 \text { part of putty and } \\
0,3 \text { parts of NHL } \\
3,5\end{array}$ & $\begin{array}{l}\text { Coarse fragments of } \\
\text { Zandobbio limestone, } \\
\text { "spolverino" (main } \\
\text { dolomia of Carenno) }\end{array}$ & $1: 2: 2$ \\
\hline
\end{tabular}

The new plaster is $1 \mathrm{~cm}$ thick without finishings. The researchers used lime as binder of the mortars, and studied two main typologies of mixtures: hydraulic mortars (adding additives to the aerial lime) and natural hydraulic mortars.

Regarding the second scope, the researchers chose the most compatible and used waterproof treatment for lime mortars, associated to a biocide that gave optimal results under previous tests (Pinna, Salvadori, \& Galeotti, 2012). The waterproof product was applied to the specimens, and tested in the laboratory; the biocide was applied on the northern facade and tested on the site.

\subsection{Test to evaluate the efficacy of the treatment}

The main aspect of the experimental research concerned the characterization of the water transport phenomena. In laboratory, the researchers tested three specimens for each type and applied the following tests:

- hygroscopic absorption

- $\quad$ water absorption by capillarity

- water vapour transmission

- moisture ring and spilling drop tests

The tests were performed twice: after the first phase before the application of the treatment and then after the application of siloxane product (SILO 111 CTS in white spirit 10\%), verifying in particular the water vapour diffusion-equivalent air layer thickness 
and the water absorption by capillarity, according to the German standard DIN4108-3 (Künzel, Künzel, \& Holm, 2004).

They applied the treatment using a brush until reaching the condition of surface saturation, then left the specimen at laboratory ambient temperature $\left(22 \pm 3^{\circ} \mathrm{C}\right)$ and Relative Humidity $(50 \pm 10 \%)$ for 30 days to guarantee the complete curing of the polymeric product, according to the standard UNI 10921.

Meanwhile in the laboratory, the researchers performed color test to evaluate the chromatic alterations caused by the application of the water repellent treatment.

On the mortars on site, the researchers performed only the tests of the moisture ring and colorimetry, and during the inspections, they observed the trend of deterioration of the different plaster without treatment exposed to natural agents.

\section{RESULTS OF LABORATORY TESTS}

\subsection{Hygroscopic absorption}

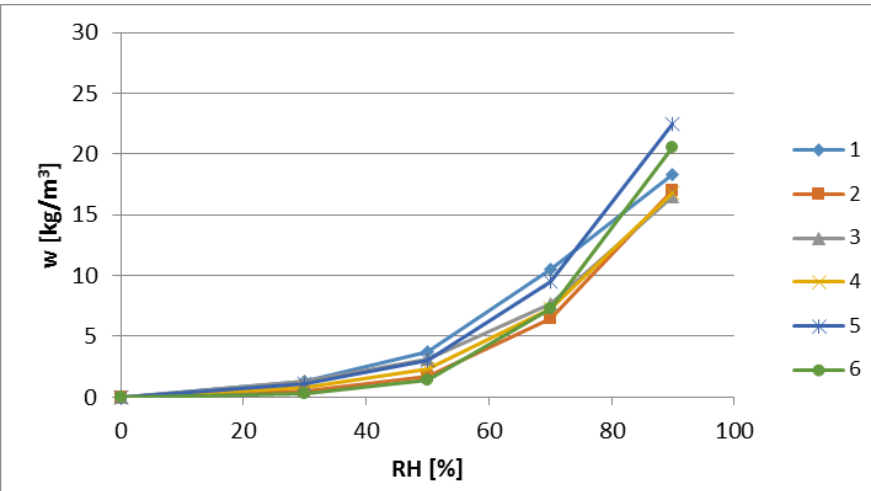

Figure 2. Relative Humidity-moisture content mass by volume (untreated specimens)

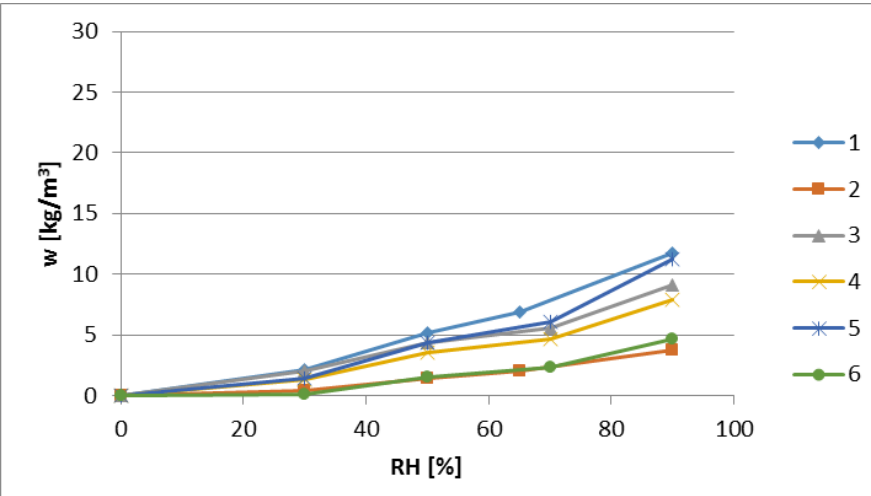

Figure 3. Relative Humidity-moisture content mass by volume (treated specimens)

The researchers executed the absorption test in the climatic chamber (standard UNI EN ISO 12571:2001), for the evaluation of the hygrothermal behavior of building materials and products (Daniotti, Erba, Moioli, Rosina, \& Sansonetti, 2014).
Considering the untreated specimens, the lowest moisture content is in mortar \# 2, 3 and 4. The differences of moisture content before and after the application of the treatment are significant: the highest reduction is in mortar \# 6, where the moisture content dropped from about $21 \mathrm{~kg} / \mathrm{m}^{3}$ to $5 \mathrm{~kg} / \mathrm{m}^{3}$.

\subsection{Water absorption by capillarity}

The researchers determined the water absorption by capillarity applying the standard UNI EN 15801: 2010. The lowest amount of water absorbed per unit area in untreated specimens is in mortar \# 3 and 4. This remains valid also after the application of the treatment.

The reduction of the absorption coefficient for all the treated mortars compared to the untreated ones is remarkable. The highest difference is in mortar \# 5 (Erba, Daniotti, Rosina, \& Sansonetti, 2015).

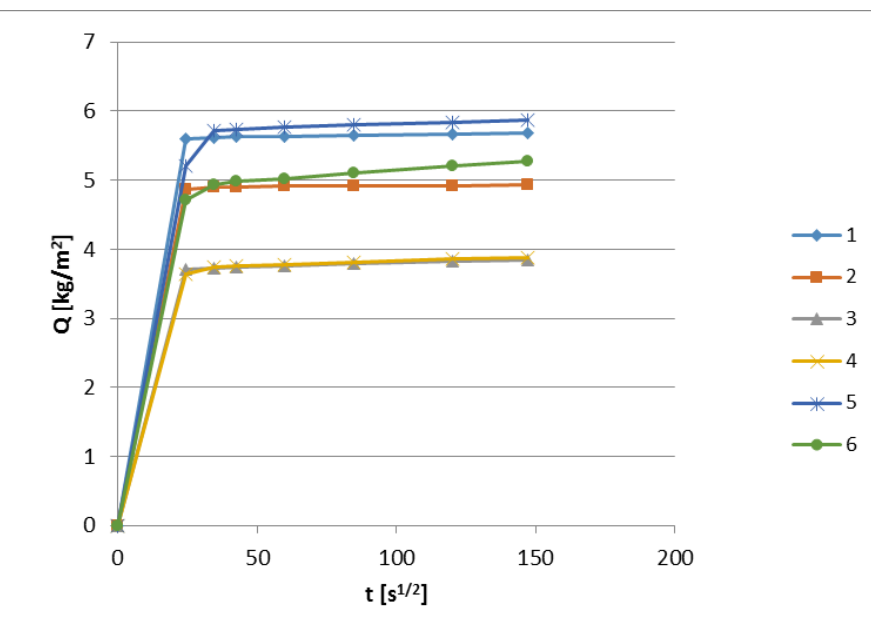

Figure 4. Curves of capillary water absorption (untreated specimens)

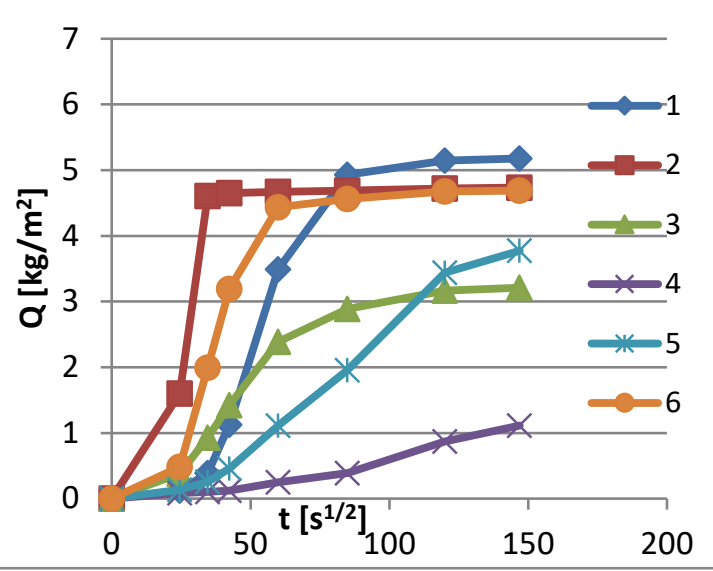

Figure 5. Curves of capillary water absorption (treated specimens) 


\subsection{Determination of water vapour transmission properties}

The test was performed following the UNI EN 15803: 2010. The researchers calculated the water vapour resistance factor $\mu$, given by the ratio between the water vapour permeability of air and that of the material concerned.

Table 3. Water vapour resistance factor for untreated/treated samples (the test refers only to samples \# 1-4).

\begin{tabular}{|c|c|c|}
\hline Type of mortar & $\begin{array}{l}\boldsymbol{\mu}[-] \\
\text { before treatment }\end{array}$ & $\begin{array}{l}\boldsymbol{\mu}[-] \\
\text { after treatment }\end{array}$ \\
\hline $\mathbf{1}$ & 12 & 12 \\
\hline $\mathbf{2}$ & 13 & 10 \\
\hline $\mathbf{3}$ & 14 & 17 \\
\hline $\mathbf{4}$ & 15 & 16 \\
\hline
\end{tabular}

The values calculated on the samples before and after the application of the water repellent treatment are almost equal: the product SILO 111 does not add resistance to the flow of vapour across the specimens.

\subsection{Moisture ring and spilling drop test}

In the laboratory, the researchers applied also innovative tests (moisture ring and spilling drop tests) on the specimens to study the characteristics of liquid water absorption and its diffusion (Sansonetti, Rosina, \& Ludwig, 2012). Nevertheless, some uncertainties on the interpretation of the results remained in both the tests, although the researchers defined two methods to reduce the misleading interpretation:

1. To analyze the profile of the temperature on the segment drawn on the thermographic image: the trend indicates the passage from dry and wet areas. With this method, it is possible to calculate the surface area of water diffusion.

2. To analyze the color pixels in the thermographic image, to obtain the percentage of the wet area compared to the total area of the specimen.

In the first case, the chosen profile corresponds to a possible circular area. In reality, the diffusion of the water depends on the pores and the specific characteristic of the material, therefore the shape is usually not a perfect circle rather it has an indefinite contour.

In the second case, the researchers found out uncertainties in the choice of the color pixel because not all the area is wet in the same way: it is possible to see different circular rings, which correspond to different colors and water absorptions.
For these reasons, the results obtained through these tests can not be considered precise enough yet.
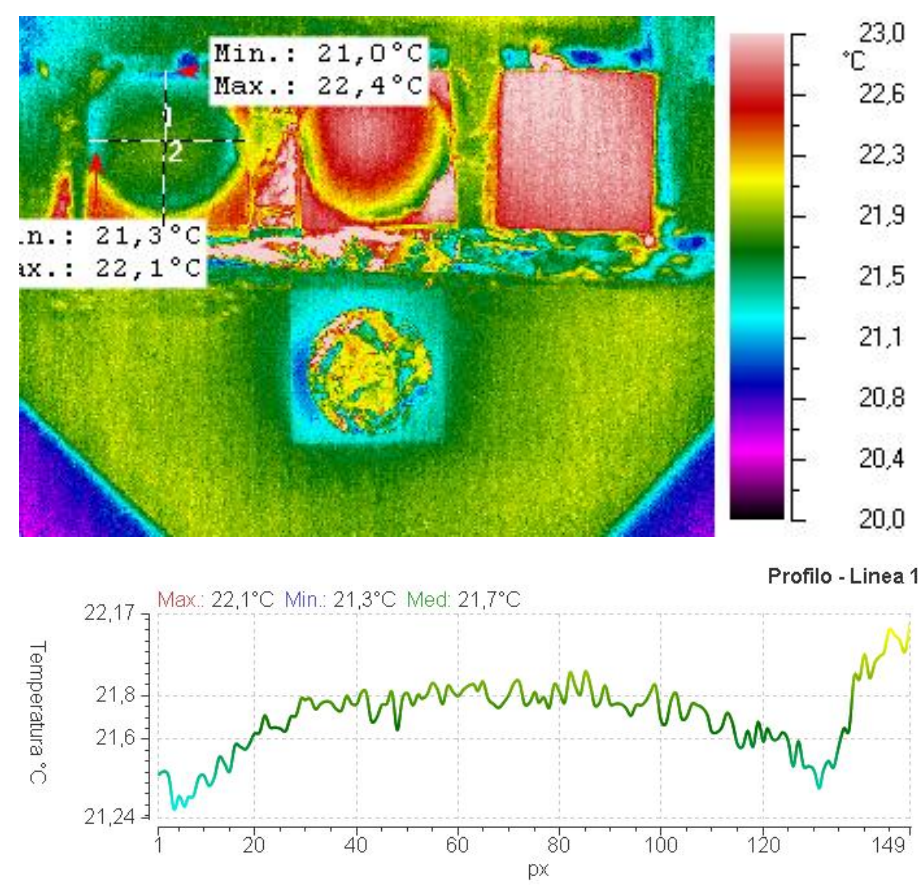

Figure 6. Definition of the segments on the thermographic image and elaboration of the surface temperature profile.

\subsection{Color test}

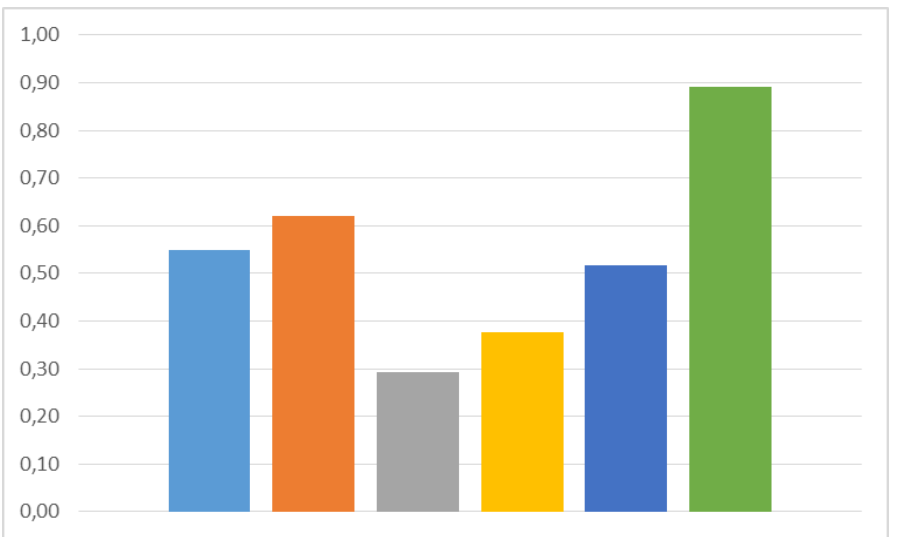

Figure 7. Total color difference $\Delta \mathrm{E}$ among the six lime mortars specimens (\#1 - 6 from left)

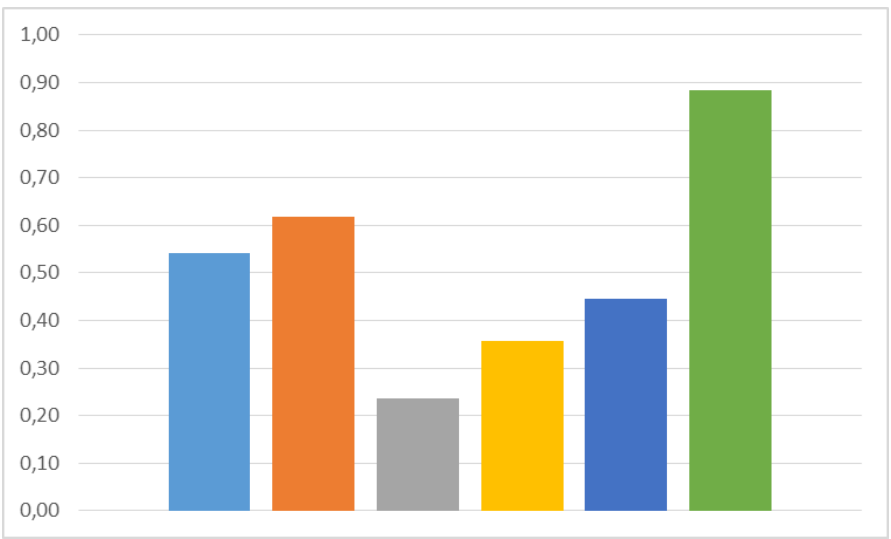

Figure 8. Total shade difference $\Delta \mathrm{H}$ among the six lime mortars specimens (\#1 - 6 from left) 
The color test results allowed the researchers to evaluate the chromatic alterations on the mortar specimens caused by the application of the water repellent treatment SILO 111 (standard UNI EN 15886:2010). From the analysis, the researchers can state that the application of the water-repellent treatment does not affect the surface color ( $\Delta \mathrm{E}$ ranging from 0,30 to 0,90 , $\Delta \mathrm{H}$ ranging from 0,20 to 0,90$)$. Values below 1 are considered very good and not perceivable by the naked eye.

\section{RESULTS TESTS ON SITES}

\subsection{Effectiveness of Biocide treatments}

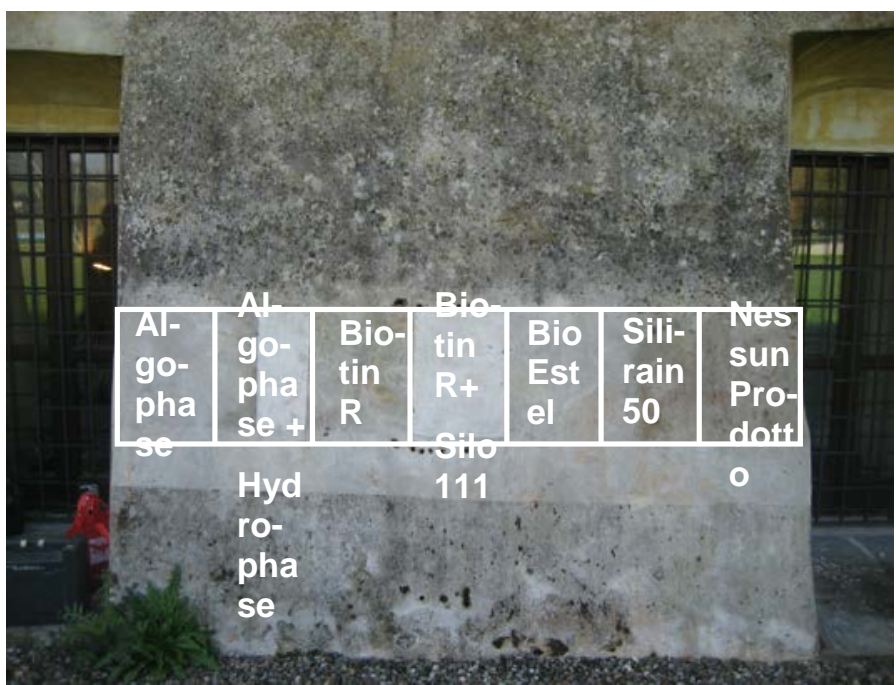

Figure 9. Plaster with the indication of biocide products (after 10 months from the products application)

On the North façade a biological patina covers the plaster surface, especially where this latter is not perfectly vertical, but inclined. It is possible to suppose that the masonry morphology facilitates to collect and retain higher amount of rainwater than the vertical ones. Three biocide products (Algophase, Biotin R, Bioestel), were used with or without the addition of a water repellent treatments

As it is possible to observe, the color of the surfaces areas (measured by a colorimeter too), treated with both Biocide and water repellent (Algophase + Hydrophase; Biotin+ Silo111) resulted almost clean after 10 months from the application of the products, those prevented the growth of algae and fungi and the consequent darkening of the plaster surface.

\section{CONCLUSIONS}

The project generated two kind of outputs: an operational result with the data for the new plaster composition and a methodological innovation, the introduction of a long run conservation approach.

Referring to the first achievement it has been clear that comparing the behavior of deteriorated plasters with samples of different mixtures would have been the best condition in order to define the suitable intervention.

On the untreated plasters applied on site, the moisture ring test gave some input for the identification of the best mixture; nevertheless, the precise interpretation of the results needs further investigation.

By visual examinations, the most durable mix design were shown to be mortars \# 3 and 4: in fact, shrinkages and drying cracks resulted in less severe damage on the surface of these testing areas compared to the surfaces of the other mixtures, especially where there were moisture stains and possible biological growth. The data processing phase is still ongoing as well as the on site investigation: the periodical measurements and the natural ageing of the applied products, together with the effects of the weathering are under study for the next five years.

Nevertheless, the investigations provided enough input data for supporting the choice of the best mixture to apply on the northern side. At the end of the building site, the performed tests and analysis implemented during the ongoing Conservation Plan in particular supported the decision process for defining the threshold between maintenance and acceptable damage, and, consequently setting the inspection procedures, cycles of maintenance of protective/biocide treatments, and the economic plan.

The second result is the integration of this scientific data within the Conservation Plan. As a first output, it pointed out both the key points and the areas affected by major risks that make decay phenomena appear. This kind of mapping has been the basis for planning the conservative actions.

In the case of the plaster, it was evident at once that besides the criticalities due to the previous works there was a problem of the durability of the material itself. In the Plan, regular checking and monitoring activities allowed to verify all the data resulted from the diagnostic campaign on the characterization of the mortars, the application techniques and the behaviour through time.

This means that each analysis is associated to the correspondent element, univocally identified in the Conservation Plan by an alphanumeric code. In the Technical Handbook there are text fields dedicated to the description of the diagnostic analyses, including type, time of execution, procedures and results. The registration of this data leads to a twofold output: the implementation of the informative system, for the 
data gathering, and the possibility to revise the scheduling of the conservation activities, depending on the results of diagnostic.

In this case, the registration of the technical procedures is the first step of a monitoring system, which will produce comparable results and defines the analyses for the assessment of durability in time.

A further output is the evaluation of scheduling new analyses in relation with the other technological elements within the system. For instance the durability of new mortars for itself it is not an indicator without a connection with the characteristics of the walls, the measure of the humidity and thus if there are not any data about the breathability of the whole system (foundation, wall, plaster and finishing). Programming an optimal control system is part of a good strategy for the care of the building, which leads to continuous care and prevention of damages.

Periodic inspections are aimed at controlling both the development of ongoing decay processes and the efficacy of preventive actions which have been carried out; on the other hand, they are useful also to guarantee that repairs are carried out in due time in order to minimize damage.

The next step should be framing such a Conservation Plan in a Management Plan, built as a tool encompassing the guidelines and the operational instructions for using the property, dealing with all the issues concerning conservation and valorisation, including the economic perspective.

\section{REFERENCES}

Fiocca, E., \& Sabatini, F. 2013. La conservazione preventiva e programmata come strategia: il caso studio del Monastero di Santa Maria del Lavello - Tesi di Laurea.

Della Torre, S. 2003. La conservazione programmata del patrimonio storico architettonico. Linee guida per il piano di manutenzione e consuntivo scientifico. Milano: Guerini e Associati.

UNI EN 15886:2010 Conservazione dei Beni Culturali - Metodi di prova - Misura del colore delle superfici.

UNI 11432:2011 Beni culturali - Materiali lapidei naturali ed artificiali - Misura della capacità di assorbimento di acqua mediante spugna di contatto.

Moreau, C., Vergès-Belmin , V., Leroux, L., Orial , G., Fronteau , G., \& Barbin , V. 2008. Water-repellent and biocide treatments: Assessment of the potential combinations. Journal of Cultural Heritage, 394-400.

Moropoulou, A. 2000. Reverse engineering to discover traditional technologies: a proper approach for compatible engineering mortars. Revue du groupe europeen d'etudes pour les techniques physiques, chimiches, biologiques et mathematiques appliqués a l'archeologie, Compatible materials for the protection of European cultural heritage, 81-107.

UNI EN ISO 12571:2001 Hygrothermal performance of building materials and products: Determination of hygroscopic properties.

UNI EN 15801:2010 Conservation of cultural property. Test methods. Determination of water absorption by capillarity.
UNI EN ISO 12572:2006 Hygrothermal performance of building materials and products. Determination of water vapour transmission properties.

Künzel, H. M., Künzel, N., \& Holm, A. 2004. Rain protection of stucco facades. Proceedings of the Performances of Envelopes of Whole Buildings IX Conference. Clearwater Beach, Florida.

UNI 10921:2001 Beni culturali - Materiali lapidei naturali ed artificiali - Prodotti idrorepellenti - Applicazione su provini e determinazione in laboratorio delle loro caratteristiche.

Daniotti, B., Erba, S., Moioli, R., Rosina, E., \& Sansonetti, A. 2014. PPC at Lavello Convent: towards a sustainable Conservation Plan after the restoration. Proceedings of the PPC Conference: Preventive and Planned Conservation. Monza-Mantova.

Erba, S., Daniotti, B., Rosina, E., \& Sansonetti A. 2015. Evaluation of moisture transfer in external plaster finishing to improve their conservation. Proceedings of the ISBP2015 Conference, Porto, Portugal.

UNI EN 15803:2010 Conservazione dei beni culturali - Metodi di prova - Determinazione della permeabilità al vapore d'acqua.

NORMAL 21/85 Permeabilità al vapor d'acqua.

UNI EN 15886:2010 Conservazione dei Beni Culturali - Metodi di prova - Misura del colore delle superfici.

Pinna, D., Salvadori, B., \& Galeotti, M. 2012. Monitoring the performance of innovative and traditional biocides mixed with consolidants and water-repellents for the prevention of biological growth on stone. Science of The Total Environment, 132-141

Sansonetti, A., Rosina, E., \& Ludwig, N., 2012. Contribution of IR Thermography to the Performance Evaluation of WaterRepellent Treatments. Restoration of Buildings and Monuments. An International Journal, 13-22 